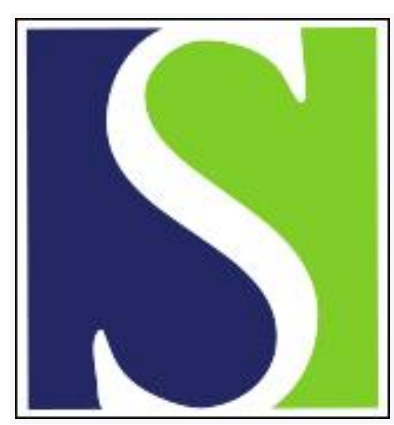

Scand J Work Environ Health 1992;18(3):186-194

https://doi.org/10.5271/sjweh.1589

Issue date: 01 Jun 1992

Design of check-out systems including laser scanners for sitting work posture.

by Hinnen U, Laubli T, Guggenbuhl U, Krueger H

Affiliation: Institute of Hygiene and Applied Physiology, Federal Institute of Technology, ETH-Zentrum, Zurich, Switzerland.

This article in PubMed: www.ncbi.nlm.nih.gov/pubmed/1615293

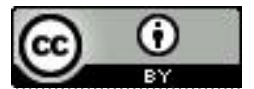




\title{
Design of check-out systems including laser scanners for sitting work posture
}

\author{
by Urs Hinnen, MD, Thomas Läubli, MD, Urs Guggenbühl, MSc, Helmut Krueger, PhD1
}

\begin{abstract}
HINNEN U, LÄUBLI T, GUGGENBÜHL U, KRUEGER H. Design of check-out systems including laser scanners for sitting work posture. Scand $J$ Work Environ Health 1992;18:186-94. Forty-six laser scanner operators were compared with 106 cashiers operating conventional cash registers. The influence of job rotation on the two groups was evaluated, and several design features were examined. For this purpose the prevalence of musculoskeletal disorders was determined by means of a questionnaire and a physical examination. In addition, a three-dimensional movement analysis system was employed. Work postures were analyzed with the Ovako working analysis system. The results indicate that a beneficial effect on the musculoskeletal system is achieved by combining the operation of a laser scanner with job rotation. The study also points out the need for better equipment, including flat scanners and smaller keyboards, and a change in the angle between the scanner and the take-off belt running up to the cashier.
\end{abstract}

Key terms: cashiers, three-dimensional movement analysis, job rotation, musculoskeletal disorders, Ovako working analysis system, supermarket.

Many modern check-out systems in supermarkets now include laser scanners that can read the bar codes attached to the purchases. In some European countries the introduction of these scanners, originally constructed for standing cash register operators, is problematic because the check-out systems have been designed for a sitting work posture. This fact is reflected in a few publications about laser scanner checkout systems in Europe $(1,2)$. The British authors (1) described significantly lower work satisfaction among cashiers operating a laser scanner compared with cash register operators working at conventional check-out counters. In addition they found a higher rate for painful shoulder and arm disorders in laser scanner operators, and this rate was due to the poor workplace design. In the French study (2), the authors described unfavorable work postures (twisting, reaching, bending) due to the design of the laser scanner counters.

One study (3) compared muscular activity during the operation of laser scanners to muscular activity during work at conventional check-out counters. It showed that operating laser scanners causes higher loads in the trapezius, infraspinatus, and thoracic spinae muscles than operating conventional cash registers does.

In order to accompany the introduction of laser scanners into Switzerland and to evaluate the best design of a check-out counter equipped with a laser scanner, a study was performed on the ergonomics, occupational health, and management aspects related to the use of laser scanners. The study was done in different

\footnotetext{
1 Institute of Hygiene and Applied Physiology, Federal Institute of Technology, ETH-Zentrum, Zurich, Switzerland.
}

Reprint requests to: Dr U Hinnen, Institut für Sozial- und Präventivmedizin der Universität Zürich, Sumatrastrasse 30, CH-8006 Zurich, Switzerland. supermarkets of the largest Swiss food distributors. The supermarkets were selected on the grounds of several design features allowing the investigation of their effects on the musculoskeletal system of the cashiers. They particularly differed in their equipment (scanner or keyboard only), their design of the bagging area (presence of a chute or unloading to a shopping cart), and work organization (job rotation or checking only).

\section{Subjects and methods}

The study included 46 laser scanner cashiers and 106 cashiers working at traditional check-out counters. The small number of laser scanner cashiers was due to the fact that, in Switzerland, only a few cash register operators were working with check-out systems including laser scanners at the time the study was performed.

The study had a cross-sectional design and therefore did not include those absent because of illness or holidays at the time the examinations were performed. Persons having had a serious injury in the past were excluded. The study also did not include four cashiers who refused to participate. Three persons who participated refused the physical examination.

All of the 152 cashiers included in the study were women. The median age was 32.5 ( $25 \%$ quartile 23 , $75 \%$ quartile 43.5 ) years. The proportion of married, unmarried, and divorced was $41.4,40.8$, and $17.8 \%$, respectively. Because a high turnover is usually seen in this kind of job, the median length of stay in the job was only two years $(25 \%$ quartile $1,75 \%$ quartile 6). Of the workers $39.5 \%$ had a part-time job and $60.5 \%$ worked full-time. Thirty-two percent had a job with job rotation, whereas $68 \%$ did only cashier work. 
The laser scanner cashiers worked in four different supermarkets, and those operating conventional cash registers worked in 13 different supermarkets. All of them used a sitting work posture.

The workstations of two of the four stores equipped with laser scanners had a design in which the scanner was situated to the left of the cashier and in which the items were carried from the conveyor belt across the scanner to a shopping cart. In the third store the scanner was also located to the left of the cashier. There the cashier took the items from a conveyor belt to scan them and then put them on another conveyor to bring them to a chute. In the fourth supermarket the scanner was located in front of the cashier and presented a horizontal beam toward her. There the items were carried from a conveyor belt across the scanner to a shopping cart.

Seven supermarkets without laser scanners had a checkstand design including a conveyor belt that brought the items to a chute. In six supermarkets the cashiers had to carry the items from the conveyor to a shopping cart.

Information about musculoskeletal disorders, also called cumulative trauma disorders, was elicited by means of a self-administered questionnaire, which was filled out under supervision during workhours. The questionnaire asked for the frequency of symptoms and their location, with the help of a diagram of the human body. It was composed of 37 items about the occurrence (never or seldom, occasionally, almost daily) of symptoms (pain, stiffness, fatigue) in 12 body regions. A similar questionnaire has been used in other studies dealing with complaints at workplaces with video display units and optical aids (4-7).

The questionnaire was supplemented by a standardized musculoskeletal checkup. All of the physical examinations were done by one physician. The physician performing this examination did not know the results of the questionnaire, but he simultaneously took a medical and occupational history.

The physical examination has been fully described earlier (8). Briefly, the physician palpated selected muscles of the neck and shoulder area (sternocleidomastoideus, scaleni, pectoralis minor, trapezius descendens, trapezius transversus, deltoid), of the back and low back (erector spinae), and the upper extremities (extensors and flexors of the forearms) to locate painful pressure points. In addition, the insertions of tendons (linea nuchae, mastoid, acromioclavicular joint, upper edge of the scapula, deltoideus insertion, epicondylus radialis, epicondylus ulnaris, sternoclavicular joint, costosternal joints, coracoclavicular connection) were checked. For the palpation of the muscles three levels of pain intensity were determined (no pain $=0$, pain only if pressure to hard obstacle $=1$, pain at little pressure $=2$ ). The rating of the palpation of the tendons had four levels (no pain $=0$, continuous pain at heavy pressure $=1$, pain at pressure to the bone $=2$, pain at little pressure on the skin $=3$ ). Both the active and passive range of motion of the neck, the glenohumeral joint, and the wrist was also tested.

As it had been shown earlier (8), the reliability of this examination scheme seems to be satisfactory; in a comparison of the sum of the findings of two independent examining teams, a Spearman correlation for ranks of 0.7 had been found.

The findings of the medical checkup (painful pressure points, range of motion) were grouped into indices that corresponded to the body parts of the questionnaire (range from 0 to 100 ; neck, right shoulder, left shoulder, right arm, left arm). A series of pressure points (eg, neck: linea nuchae and mastoid) and range of motion tests $(\mathrm{eg}$, range of motion of both shoulders) never or almost never yielded a positive finding and therefore were not included in the index. For the same reason no useful index for the back and the wrist could be created. In order that these indices could be applied in the logistic regression, a value of $<10$ was defined as 0 , one of $\geq 10$ as 1 .

So that the actual work conditions of the cashiers could be described, an ergonomic check was performed in all 17 supermarkets. In addition the numbers of handled items were recorded for different types of check-out systems. Furthermore a group of participants underwent supplementary investigations. The work postures of four cashiers and 25 shop assistants (10 selling delicatessen or bakery products, 15 filling up shelves) were recorded following the method of OWAS (Ovako working analysis system). OWAS is a method with which to study the load of the musculoskeletal system at the workplace. It mainly consists of a series of work posture observations carried out in a fixed frequency $(9-11)$. Since this method is too "largely meshed" for a comparison between different check-out stand designs, OWAS was used to describe the influence of job rotation on the biomechanical stresses of cashier work.

The cashiers were randomly selected and were observed for $15 \mathrm{~min}$ at intervals of $15 \mathrm{~s}$. The average observation time for each randomly selected shop assistant was $30 \mathrm{~min}$, during which 60 data were collected at intervals of $30 \mathrm{~s}$. Every observation was registered in a scheme of 84 different work postures, whereas the postures of the head were recorded separately. The observation also included a differentiation of the musculoskeletal strain (static or dynamic) for several body parts (head, spine, arms, legs). The inference was done by computing the frequencies of the different body postures and giving each of them a weight with respect to harmfulness. The following four action categories (AC) were distinguished: AC1: normal posture, no action required; AC2: the load of the posture slightly harmful, actions to change the posture should be taken in the near future; $\mathrm{AC} 3$ : the load of the posture distinctly harmful, actions to change the posture should be taken as soon as possible; AC4: the load of the posture extremely harmful, actions to change the posture should be taken immediately. 
In addition the pattern of movements was measured with a specially developed movement analysis system $(12,13)$. The left wrist, the left elbow, and both acromions were marked with an ultrasonic emitter. Four microphones were arranged in a plane just above the subject. These received the emitted short acoustic signals. The time differences between the signals traveling from the emitter to the different microphones were calculated. The signals were emitted 50 times per second, and the calculated three-dimensional coordinates had a spacial resolution of approximately $0.5 \mathrm{~mm}$.

Every second, a personal computer calculated the medians and the lower and upper quartiles of the parameters of the motographic study (angle of the left elbow, distance of the left hand to the left shoulder, velocity of the left hand).

These measurements included nine cashiers operating laser scanners ( 6 with a vertical laser beam, 3 with a horizontal laser beam) and eight persons working with conventional check-out systems.

To compare the rate of complaints in different occupational groups, the chi-square test with Yates' correction was performed (14). Unconditional logistic regression was used to examine the influence of different variables on the frequency of musculoskeletal disorders (15). Within the subgroups the MantelHaenszel analysis for $\mathrm{K} 2 \times 2$ tables was performed calculating Mantel-Haenszel summary odds ratios and 95\% confidence intervals using the Robins variance. The analysis also included the Overall Mantel-Haenszel Test for Association and Woolf's test of heterogeneity of odds ratios. This part of the statistical evaluation used a STATA version that was supplemented by a computing program written by I Kamae (Harvard University, Boston). Finally, to test the correlation between the results of the questionnaire and those of the medical evaluation, linear regression was carried out (15).

\section{Results}

\section{Musculoskeletal disorders}

Information on the frequency of musculoskeletal disorders in the back and upper limbs was gathered from
152 checkers by questionnaire. A high prevalence of complaints about pain was particularly found for the neck, the left shoulder, the left arm, and the back. The comparison with female office workers who had been studied by means of the same questionnaire showed that particularly the frequency of complaints about pain in the left shoulder and the left arm was extraordinarily high (table 1).

An additional physical examination focused on the shoulder, neck, and arm area. An index of 10 and higher was considered to be a sign of an occupational disorder if the medical history did not reveal other reasons for the findings. The highest index was found for the left shoulder (median 25, 25\% quartile 12, 75\% quartile 50). Seventy-six percent of the examined cashiers had an index of 10 or higher. Sixty-one percent of the cashiers had a right shoulder index that indicated a substantial disorder (median 16, 25\% quartile $5,75 \%$ quartile 30 ). The frequency of cashiers having signs of a musculoskeletal disorder in the arms or the neck ranged from 17 to $19 \%$.

The correlation between the results of the questionnaire and those of the medical evaluation was examined by simple linear regression. Generally, a significant, but weak linear relationship was found, based on the coefficient of determination $r^{2}\left(r^{2} 0.031-\right.$ 0.182 ).

Multivariate logistic regression was performed to evaluate the effect of scanning on the rate of musculoskeletal disorders in comparison with cashier work with keyboards only (table 2). Besides workplace design features, the model included several confounding factors, taking into account age, marital status, kind of job (part-time or full-time), length of stay on the job, and length of work as a cashier.

A strong interaction between the factors "scanning versus keying" and "job rotation versus no job rotation' and a somewhat weaker but still significant interaction between "scanning versus keying" and "workplace with versus workplace without chute" was found. Therefore the results in table 1 have to be interpreted with caution. As it will be shown later in this section (table 3), the interaction mentioned first may be largely responsible for the putative general tendency of fewer complaints among cashiers operating laser

Table 1. Questionnaire results on pain in various body parts among female workers - percentage with daily or occasional symptoms; numerals in italics indicate a significantly higher percentage than in the other groups (NS = not significant)

\begin{tabular}{|c|c|c|c|c|c|c|c|c|}
\hline \multirow{2}{*}{ Group of workers } & \multirow{2}{*}{ Neck } & \multirow{2}{*}{ Low back } & \multicolumn{3}{|c|}{ Right side } & \multicolumn{3}{|c|}{ Left side } \\
\hline & & & Shoulder & Arm & Hand & Shoulder & Arm & Hand \\
\hline $\begin{array}{l}\text { Cashiers } \\
\text { Data entry off line } \\
\text { Data processing on line } \\
\text { Typists } \\
\text { Domestic directory assistance } \\
\text { Foreign directory assistance }\end{array}$ & $\begin{array}{l}48 \\
56 \\
34 \\
49 \\
48 \\
44\end{array}$ & $\begin{array}{l}55 \\
64 \\
57 \\
57 \\
66 \\
56\end{array}$ & $\begin{array}{l}22 \\
45 \\
20 \\
19 \\
22 \\
19\end{array}$ & $\begin{array}{r}24 \\
58 \\
22 \\
12 \\
12 \\
7\end{array}$ & $\begin{array}{l}24 \\
44 \\
34 \\
20 \\
17 \\
19\end{array}$ & $\begin{array}{l}41 \\
25 \\
15 \\
22 \\
17 \\
17\end{array}$ & $\begin{array}{r}39 \\
25 \\
15 \\
16 \\
7 \\
2\end{array}$ & $\begin{array}{r}25 \\
16 \\
19 \\
14 \\
14 \\
7\end{array}$ \\
\hline $\begin{array}{l}\text { Chi squarea } \\
\text { P-value }\end{array}$ & $\begin{array}{l}2.9 \\
\text { NS }\end{array}$ & $\begin{array}{l}7.1 \\
\text { NS }\end{array}$ & $\begin{array}{r}17.3 \\
0.004\end{array}$ & $\begin{array}{r}14.3 \\
0.014\end{array}$ & $\begin{array}{l}7.7 \\
\text { NS }\end{array}$ & $\begin{array}{r}16.6 \\
0.005\end{array}$ & $\begin{array}{r}21.5 \\
0.001\end{array}$ & $\begin{array}{l}8.2 \\
\text { NS }\end{array}$ \\
\hline
\end{tabular}

a Degrees of freedom $=5$. 
scanners in that the effect of scanning very strongly depends on the organization of the cashier work (job rotation). However, the results indicate unquestionably that working with laser scanners is less stressful for the right arm and the right hand than operating a traditional check-out system without a scanner. This finding is presumably due to the fact that the use of the keyboard by the right hand has largely been omitted.

It has to be mentioned that almost none of the confounding factors originally corrected for in the logistic regression proved to have a significant effect on the frequency of musculoskeletal disorders. Only two times did one of the confounders have to be included in the final model. Namely, the frequency of complaints about back pain was significantly influenced by the kind of job (part-time or full-time). In addition, age was an important factor for the frequency of pathological findings in the neck. Because of the strong interaction described and the insignificance of the confounders, a stratified Mantel-Haenszel analysis was performed separately for the cashiers with scanners and for those without scanners. The stratification only in- cluded the two independent variables of interest (tables 3 and 4).

Concerning the effect of the job rotation on the prevalence of musculoskeletal disorders, the results of the medical evaluation are inconsistent for the cashi-

Table 2. Risk of musculoskeletal disorders among nonscanner checkers $(\mathrm{N}=106)$ compared with scanner checkers $(\mathrm{N}=46$ ) according to the type of data collected. (OR=odds ratio, $95 \% \mathrm{Cl}=95 \%$ confidence interval)

\begin{tabular}{lccccc}
\hline \multirow{2}{*}{ Part of the body } & \multicolumn{2}{c}{ Questionnaire } & & \multicolumn{2}{c}{$\begin{array}{c}\text { Physical } \\
\text { examination }\end{array}$} \\
\cline { 2 - 3 } \cline { 6 - 7 } & OR & $95 \% \mathrm{Cl}$ & & OR & $95 \% \mathrm{Cl}$ \\
\hline Neck & 1.5 & $0.7-3.3$ & & 0.7 & $0.3-2.0$ \\
Right shoulder & 0.8 & $0.3-2.1$ & & 1.7 & $0.8-3.6$ \\
Left shoulder & 1.7 & $0.7-3.7$ & & 2.1 & $0.9-4.9$ \\
Right arm & 5.0 & $1.4-14.2^{*}$ & & 4.5 & $1.0-20.8^{*}$ \\
Left arm & 1.4 & $0.7-3.1$ & & 1.6 & $0.5-4.9$ \\
Right hand & 3.7 & $1.3-11.2^{*}$ & &. & \\
Left hand & 2.4 & $0.9-6.2$ & &. & \\
Back & 1.7 & $0.8-3.6$ & &. & \\
\hline
\end{tabular}

* Difference significant $(95 \%$ Confidence interval does not include 1).

Table 3. Risk of musculoskeletal disorders among the nonscanner checkers according to whether or not there was job rotation and whether or not a chute was used. (Mantel-Haenszel analysis, $\mathrm{N}=106$ ) $[\mathrm{OR}(\mathrm{MH})=$ odds ratio, $95 \% \mathrm{Cl}=95 \%$ confidence interval]

\begin{tabular}{|c|c|c|c|c|c|c|c|c|}
\hline \multirow{3}{*}{ Part of the body } & \multicolumn{4}{|c|}{ No job rotation versus job rotation } & \multicolumn{4}{|c|}{ No chute versus chute } \\
\hline & \multicolumn{2}{|c|}{ Questionnaire } & \multicolumn{2}{|c|}{ Physical examination } & \multicolumn{2}{|c|}{ Questionnaire } & \multicolumn{2}{|c|}{ Physical examination } \\
\hline & OR $(\mathrm{MH})$ & $95 \% \mathrm{Cl}$ & $\mathrm{OR}(\mathrm{MH})$ & $95 \% \mathrm{Cl}$ & OR $(\mathrm{MH})$ & $95 \% \mathrm{Cl}$ & OR $(\mathrm{MH})$ & $95 \% \mathrm{Cl}$ \\
\hline Neck & 0.6 & $0.2-1.4$ & 1.1 & $0.4-3.4$ & 1.6 & $0.7-3.4$ & 1.2 & $0.5-3.3$ \\
\hline Right shoulder & 0.7 & $0.3-2.0$ & 1.1 & $0.4-2.7$ & 1.1 & $0.4-2.7$ & 1.4 & $0.6-3.2$ \\
\hline Left shoulder & 0.6 & $0.2-1.4$ & 0.8 & $0.3-2.5$ & 1.9 & $0.9-4.3$ & 1.8 & $0.6-4.8$ \\
\hline Right arm & 1.3 & $0.5-3.6$ & 2.4 & $0.7-8.2$ & 1.3 & $0.6-3.0$ & 0.4 & $0.1-1.1$ \\
\hline Left arm & 0.7 & $0.3-1.8$ & $\because$ & . & 2.9 & $1.3-6.5^{*}$ & 0.7 & $0.3-1.9$ \\
\hline Right hand & $\cdot$ & . & . & . & 0.8 & $0.3-1.8$ & $\cdot$ & . \\
\hline Left hand & 0.6 & $0.2-1.7$ & . & . & 1.9 & $0.8-4.5$ & . & . \\
\hline Back & 0.4 & $0.2-1.1$ & . & . & 1.3 & $0.6-2.9$ & . & . \\
\hline
\end{tabular}

* Difference significant $(95 \%$ Confidence interval does not include 1).

Table 4. Risk of musculoskeletal disorders among the scanner checkers according to whether or not there was job rotation and whether or not a chute was used. (Mantel-Haenszel analysis, $\mathrm{N}=46$; univariate $\mathrm{OR}$ and $\mathrm{chi}^{2}(\mathrm{MH})$ if $\mathrm{OR}(\mathrm{MH})$ infinite because of multiple zero celis) [OR $(\mathrm{MH})=$ odds ratio, $95 \% \mathrm{Cl}=95 \%$ confidence interval]

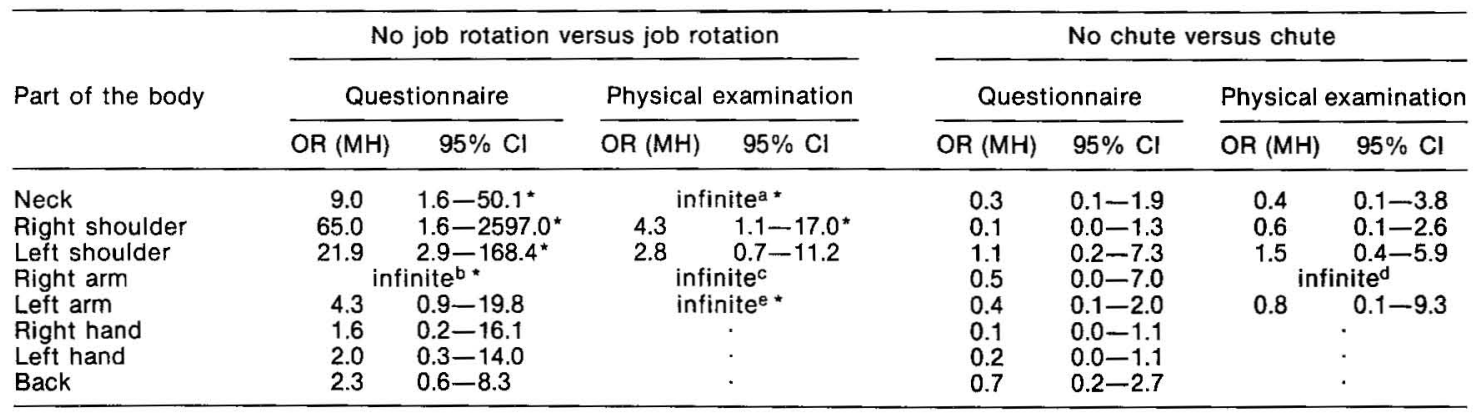

a OR uncorrected $=23.18, \mathrm{chi}^{2}(\mathrm{MH})=8.43, \mathrm{P}=0.004$.

b OR uncorrected $=9.88, \mathrm{chi}^{2}(\mathrm{MH})=3.79, \mathrm{P}=0.05$.

c OR uncorrected $=5.00$, chi $^{2}(\mathrm{MH})=1.04, \mathrm{P}=0.31$.

e OR uncorrected $=2.90, \mathrm{chi}^{2}(\mathrm{MH})=0.42, \mathrm{P}=0.52$.

d OR uncorrected $=12.69, \mathrm{chi}^{2}(\mathrm{MH})=4.41, \mathrm{P}=0.04$.

* Difference significant (95\% Confidence interval does not include 1). 
ers working at check-out stands without a laser scanner. As shown in table 3, the questionnaire results even suggest a slight disadvantageous influence of job rotation on cashiers only operating a keyboard.

The contrary was true for those operating laser scanners. A remarkable lower rate of musculoskeletal disorders was revealed for those working with job rotation. Consistent results were found when the questionnaire responses and the findings of the physical examination were analyzed. Looking at the influence of the availability of a chute, generally inconsistent results were seen. However, a clear advantage of the presence of a chute was found for the left shoulder for those working without a laser scanner (table 3).

On the other hand, no beneficial influence of the chute could be demonstrated for the scanning group. An explanation for this result may be that just one supermarket had check-out stands designed for a laser scanner and a chute. The design of the workstations in this supermarket was unfavorable in that there was no legroom to allow a person normal sitting behavior, and therefore the cashier made long reaches in connection with a high rate of bending and frequent torsion of the spine.

In figures 1 and 2 , the study population was divided into four groups differing in the presence or absence of a laser scanner in respect to job rotation. The charts of the different groups clearly demonstrate that the combination of scanning and job rotation had a very beneficial impact on the frequency of musculoskeletal disorders. But the figures also indicate that, among all of the cashiers, the scanner operators without job rotation had the highest rates of pain in the neck, the shoulders, and the left arm.
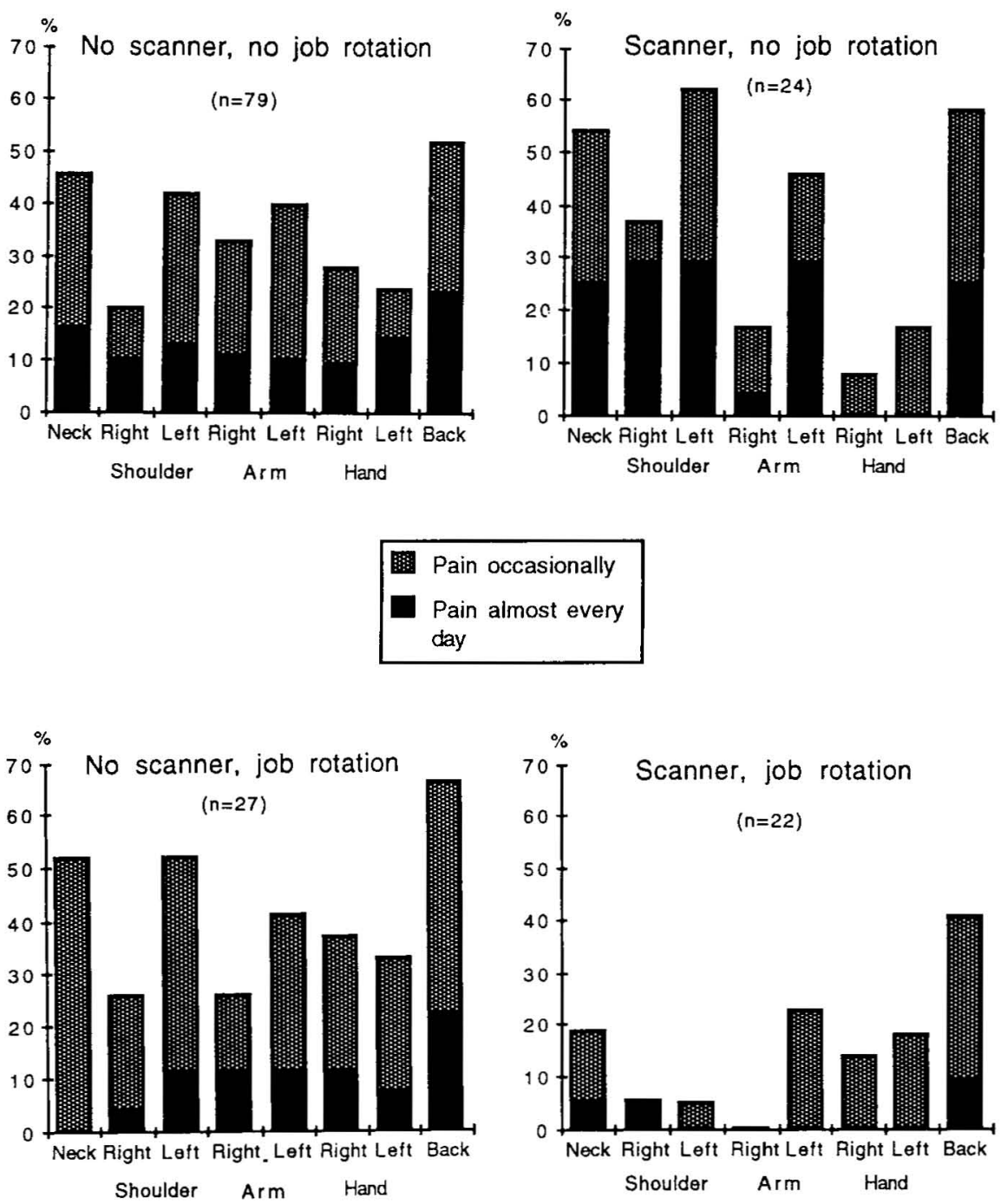

Figure 1. Questionnaire results on the feelings of pain. 


\section{Additional ergonomic investigations}

The frequency of the handled items was recorded comparing scanner check-out systems with traditional ones. The frequency was almost similar (scanner 24 items/ min; traditional 25 items/min; time for collecting money, waiting for customers, etc not included).

The motographic study compared areas of stay of the left hand at the scanner counter with those at conventional counters. Whereas no specific difference was found in the horizontal plane, it was seen in the vertical plane that the 95 percentile regularly reached the 0 -mm level for traditional counters in contrast to scanner counters, for which no such area of stay directly above the conveyor existed (figure 3 ). This finding supports the assumption that the scanner operators have to lift the items to scan them, whereas the other cashiers often slide them smoothly without lifting.

It was also found that the use of scanners (with vertical as well as horizontal beam) was more dynamic than handling items without a laser scanner, since the average range between the quartiles of the left elbow angle and of the left hand-shoulder distance ( 27 degrees and $72 \mathrm{~mm}$, respectively) was higher for the scanner operators than for the other cashiers (23 degrees and $64 \mathrm{~mm}$, respectively). The velocity of the left hand was high while operating scanners with a vertical beam $(37 \mathrm{~mm} / 0.1 \mathrm{~s}$ ) compared with the velocities during the operation of scanners with a horizontal beam $(29 \mathrm{~mm} /$ $0.1 \mathrm{~s})$ or of check-out systems without a scanner $(29 \mathrm{~mm} / 0.1 \mathrm{~s})$. The analysis also revealed that in most of the scanner workstations the laser scanner was positioned too far away from the cashier since only the closest part of it was used (figure 4). This finding was due to the unfavorable dimensions (in particular the thickness) of the laser scanners generally used in the investigated supermarkets in that they did not allow sufficient legroom underneath them if located in front of the cashier.
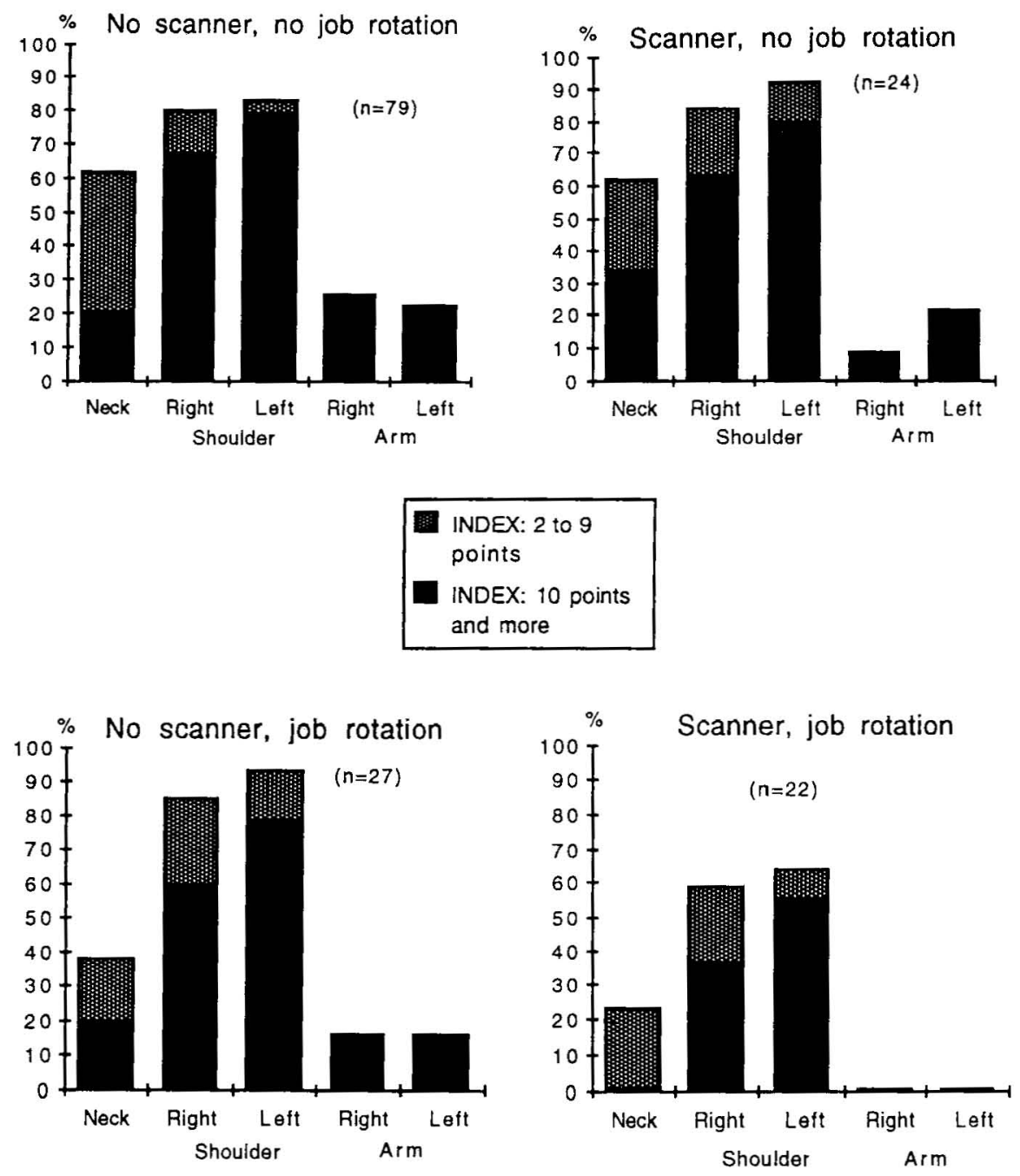

Figure 2. Results of the physical examination for pain provoked by palpation and the restriction of mobility (indices). 


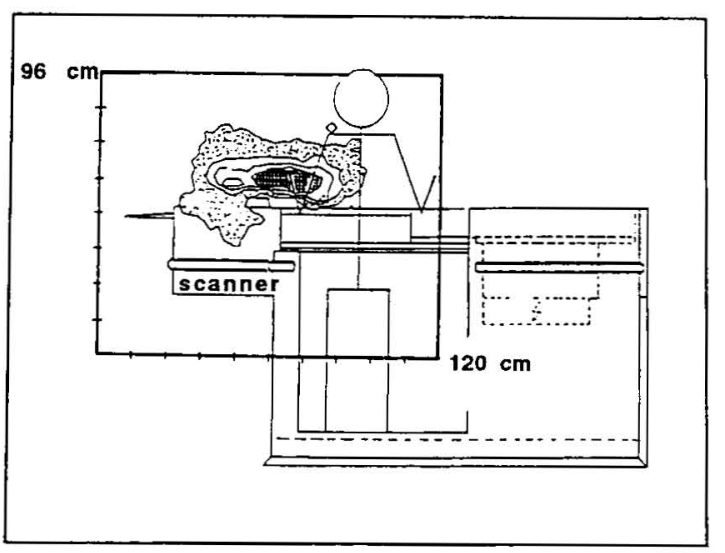

$20 \%$ percentile ( $80 \%$ of the time outside that area)

$\square 50 \%$ percentile $(50 \%$ of the time outside that area)

(a) $95 \%$ percentile (05\% of the time outside that area)

Figure 3. Frequencies of stay of the left hand during handling items at a check-out counter equipped with a laser scanner (one cashier, registration time $60 \mathrm{~min}$, recording frequency $50 \mathrm{~Hz}$, vertical plane)

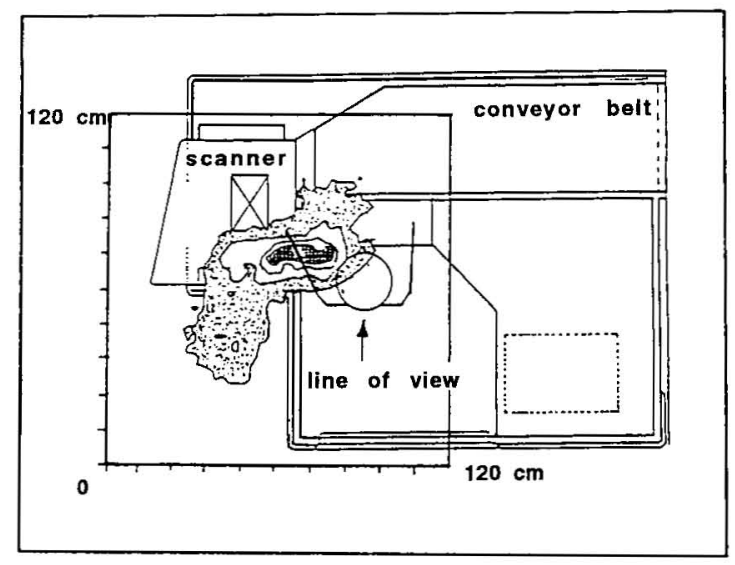

$20 \%$ percentile $(80 \%$ of the time outside that area)

$\square 50 \%$ percentile (50\% of the time outside that area)

[.: $95 \%$ percentile (05\% of the time outside that area)

Figure 4. Frequencies of stay of the left hand during handling items at a check-out counter equipped with a laser scanner (one cashier, registration time $60 \mathrm{~min}$, recording frequency $50 \mathrm{~Hz}$, horizontal plane)

Table 5. Percentage of time spent in particular postures according to the Ovako working analysis system and the resulting action categories. During cashier work: 260 observations; during tasks other than cashier work (selling delicatessen or bakery products, filling up shelves): 1262 observations. Postures occurring less than $2 \%$ of the observation time are not listed.

\begin{tabular}{|c|c|c|c|c|c|c|c|c|}
\hline \multirow{3}{*}{$\begin{array}{l}\text { Postures of the } \\
\text { body parts }\end{array}$} & \multicolumn{4}{|c|}{ Cashier work } & \multicolumn{4}{|c|}{ Tasks other than cashier work } \\
\hline & \multicolumn{2}{|c|}{ Dynamic + static } & \multicolumn{2}{|c|}{ Static only } & \multicolumn{2}{|c|}{ Dynamic + static } & \multicolumn{2}{|c|}{ Static only } \\
\hline & $\%$ & $\begin{array}{l}\text { Action } \\
\text { category }\end{array}$ & $\%$ & $\begin{array}{l}\text { Action } \\
\text { category }\end{array}$ & $\%$ & $\begin{array}{l}\text { Action } \\
\text { category }\end{array}$ & $\%$ & $\begin{array}{l}\text { Action } \\
\text { category }\end{array}$ \\
\hline \multicolumn{9}{|l|}{ Back } \\
\hline $\begin{array}{l}\text { Straight } \\
\text { Bent } \\
\text { Twisted } \\
\text { Bent and twisted }\end{array}$ & $\begin{array}{r}89 \\
3 \\
6 \\
2\end{array}$ & $\begin{array}{l}1 \\
1 \\
1 \\
1\end{array}$ & $\begin{array}{r}89 \\
3 \\
6 \\
2\end{array}$ & $\begin{array}{c}1-2 \\
1 \\
1 \\
1\end{array}$ & $\begin{array}{r}80 \\
18 \\
1 \\
1\end{array}$ & $\begin{array}{l}1 \\
1 \\
1 \\
1\end{array}$ & $\begin{array}{r}64 \\
17 \\
1 \\
1\end{array}$ & $\begin{array}{c}1 \\
1 \\
1 \\
2\end{array}$ \\
\hline \multicolumn{9}{|l|}{ Arms } \\
\hline $\begin{array}{l}\text { Both arms under } \\
\text { shoulder level } \\
\text { One arm at or above } \\
\text { shoulder level }\end{array}$ & 99 & 1 & 58 & 1 & 91 & 1 & 74 & $\begin{array}{c}1-2 \\
1\end{array}$ \\
\hline \multicolumn{9}{|l|}{ Legs } \\
\hline $\begin{array}{l}\text { Sitting, legs under } \\
\text { buttock level } \\
\text { Standing, legs straight } \\
\text { Standing or kneeling, }\end{array}$ & $\begin{array}{r}99 \\
1\end{array}$ & $\begin{array}{l}2 \\
1\end{array}$ & $\begin{array}{r}99 \\
1\end{array}$ & $\begin{array}{l}2 \\
1\end{array}$ & $\begin{array}{r}0 \\
78\end{array}$ & $\stackrel{1}{1-2}$ & $\overline{78}$ & $\frac{-}{1-2}$ \\
\hline $\begin{array}{l}\text { one leg bent at knee } \\
\text { Walking or moving }\end{array}$ & $\begin{array}{l}0 \\
0\end{array}$ & $\begin{array}{l}1 \\
1\end{array}$ & - & $\overline{-}$ & $\begin{array}{r}3 \\
17\end{array}$ & $\frac{1-2}{1}$ & $\begin{array}{l}3 \\
0\end{array}$ & $\begin{array}{l}2 \\
1\end{array}$ \\
\hline \multicolumn{9}{|l|}{ Head } \\
\hline $\begin{array}{l}\text { Free } \\
\text { Bent forward } \\
\text { Bent backward } \\
\text { Twisted }\end{array}$ & $\begin{array}{r}61 \\
2 \\
0 \\
37\end{array}$ & $\begin{array}{l}1 \\
1 \\
1 \\
2\end{array}$ & $\begin{array}{r}57 \\
\frac{2}{27}\end{array}$ & $\begin{array}{l}1 \\
-1 \\
2\end{array}$ & $\begin{array}{r}68 \\
29 \\
2 \\
0\end{array}$ & $\frac{1}{1-2}$ & $\begin{array}{r}65 \\
28 \\
2 \\
-\end{array}$ & $\begin{array}{c}1 \\
2 \\
1-2 \\
-\end{array}$ \\
\hline
\end{tabular}

a $1=$ normal posture, no remedial action needed, $2=$ load of the posture slightly harmful, remedial action needed in the near future, $3=$ load of the posture distinctly harmful, remedial action needed as soon as possible, $4=$ load of the posture extremely harmful, remedial action needed immediately.

Furthermore the work postures of the cashiers in comparison with those the of shop assistants were registered with the OWAS method. The typical work posture of the cashier was sitting, with the legs under the buttock level, the back straight, and both arms under the shoulder level ( $89 \%$ of the observation time). In contrast to the cashiers, shop assistants selling fresh food (delicatessen or bakery) spent most of their time 
standing ( $66 \%$ of the observations) or walking $(18 \%$ of the observations), with back straight, and both arms under the shoulder level. Typical work postures for the workers filling shelves were standing $(45 \%)$ or walking $(15 \%)$ with back straight and arms below the shoulder level. During $16 \%$ of the observations they were standing with straight legs, back bent, and arms below shoulder level.

The results characterizing the postures of the body parts are listed in table 5 . This table shows the high percentage of static work load of the legs (AC 2), the back (AC 1-2), and the arms (AC 2) among the cashiers, and it also shows that the head was frequently (37\% of the observation time) twisted (AC 2). By way of contrast a different pattern of postures was found for the shop assistants selling delicatessen or bakery products or filling the shelves. The results demonstrate that mainly the legs and the spine were stressed considerably, but that there was also a substantial static load on the neck and the arms.

\section{Discussion}

The study was limited by its cross-sectional design and therefore probably underestimated the prevalence of disorders of the musculoskeletal system, since those having quit their job because of disabling health problems were not counted in the evaluation. It also has to be mentioned that the comparison of cashiers operating a laser scanner with those working in conventional check-out systems was afflicted with the problem that many scanning cashiers had not worked longer than one year with the laser scanner and that some of them had worked earlier at counters without a scanner. This problem reflects the small experience with laser scanners in Switzerland and therefore does not allow comment on the long-term effects of scanning. Moreover it cannot completely be ruled out that there was a selection of personnel to jobs where scanner check-out systems were introduced for the first time, although the introduction evidently did not lead to a higher fluctuation of personnel in the affected supermarkets.

It could also be argued that laser scanners have been adopted in the first place in high load or otherwise problematic supermarkets, although the participating companies assured us that the only criteria for the installation of scanners had been "good infrastructure," "easiness to survey," and "forthcoming renovation." The study also had its limitation in the methodology of the ergonomic investigation. The motographic study performed was originally designed for laboratory experiments and had not been tested in field research before. Although it proved to be a valid instrument for describing the characteristics of sedentary work tasks, it was still afflicted with a considerable rate of errors that hampered heavily the statistical analysis of the results. For this reason, no significance testing has been presented in this paper.
The evaluation of the prevalence of musculoskeletal disorders among cashiers made apparent a high frequency of problems with the neck, the left arm, the left shoulder, and the back. Especially the left shoulder and the left arm was markedly more stressed than among office workers who had been investigated earlier by the same questionnaire. This result is understandable considering that handling the items by the left hand is a highly repetitive task that is often connected with a constrained sitting posture.

At first sight it may be surprising that cashiers working only part-time do not have fewer musculoskeletal problems (except in the back) than full-time employees. Yet this finding could be explained by the fact that part-time cashiers are essentially hired to fill in the peak load periods.

It was found that the introduction of the laser scanner did not reduce the load on those parts of the body which are stressed the most. On the contrary the results of the medical evaluation suggest that the operation of a laser scanner is even more stressful for the left shoulder and the left arm than the operation of a conventional check-out counter if the job does not include job rotation. An explanation for this result is given by the three-dimensional movement analysis, which demonstrated that every item had to be lifted while it was being handled at a laser scanner and it was not slid smoothly as it is often done at conventional counters. On the other hand, the introduction of the laser scanners reduced the biomechanical stress on the right arm and the right hand since the use of the keyboard by the right hand has largely been omitted.

According to the rating scheme of OWAS, the load on several parts of the musculoskeletal system exceeded the tolerable limit of cashiers and shop assistants when they worked $8 \mathrm{~h}$ a day. This result will require action in the near future. Moreover the OWAS analysis also yielded a clear difference between the temporal distribution of the work postures of the cashiers and those of the shop assistants. This result suggests that job rotation between cashiers and shop assistants could markedly reduce the biomechanical strain of many body postures. Job rotation could lead to a diversification of the pattern of body postures and could significantly shorten the duration of certain incriminating tasks. In fact, a significant reduction in the number of complaints and medical findings in laser scanner operators occurred if they did job rotation. The scanner checkout system therefore seems to be strongly qualified for job rotation, and a beneficial impact of the introduction of laser scanner technology is achieved if it is combined with job rotation, for using a laser scanner is not a task whose efficiency can be essentially improved if more time is spent performing it. The contrary is true for cashiers keying in every purchase. The more purchase prices cashiers memorize, the faster they are able to work since they do not have to look for the labels of the purchased items. As a consequence, interruptions by other tasks are not estimated 


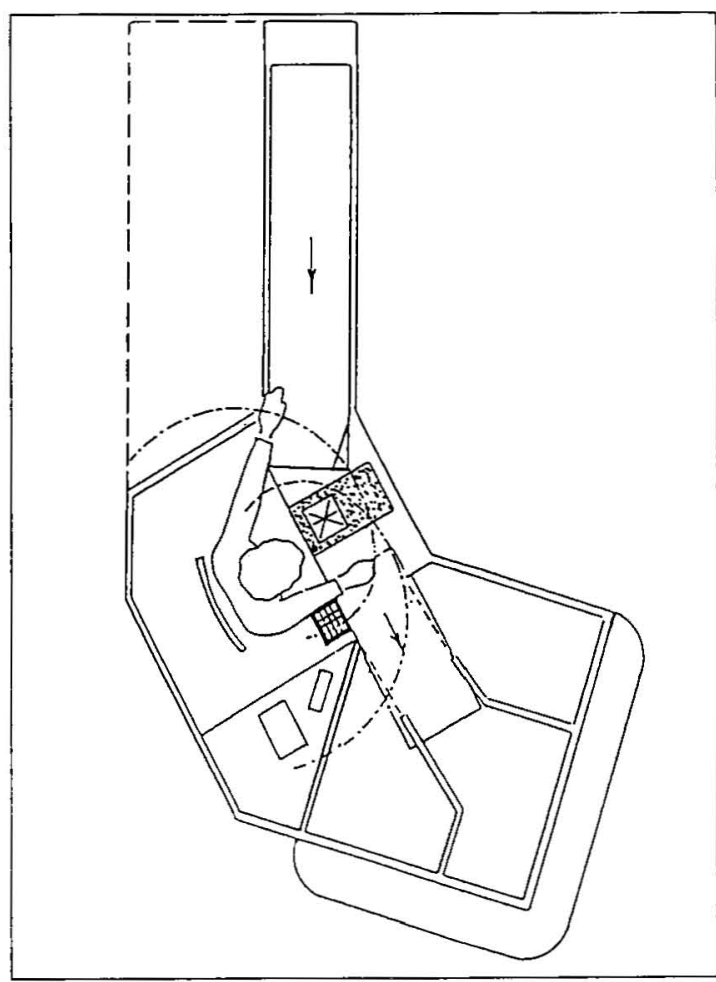

Figure 5. Proposal for the design of a check-out counter equipped with a laser scanner.

and seem to be experienced as an additional stress. When this fact is considered, it is understandable that job rotation did not reveal any advantages for cashiers operating conventional cash registers.

For a better design of check-out counters equipped with laser scanners, cash drawers, keyboards, and laser scanners are needed whose dimensions are small enough to be located in front of the cashier. In particular, flat scanners (thickness not more than $120 \mathrm{~mm}$ ) must be incorporated so that there will be sufficient legroom for the cashier. The OWAS study also indicated the need for squaring off the takeoff belt running up to the cashier (at least 30 degrees) (figure 5), because an unfavorably high frequency of head twisting was found that indicated that the items approaching on the take-off belt at an angle of 180 degrees could not be seen early enough during the scanner operation.

\section{Acknowledgments}

This study was supported by grants from the Swiss National Foundation and Swiss food distributors.

\section{References}

1. Wilson JR, Grey SM. Reach requirements and job attitudes at laser-scanner check-out systems. Ergonomics 1984;27:1247-66.

2. Gelin JM. Un code qui chance le travail. Anact, lettre d'information de l'Agence nationale pour l'amelioration des conditions de travail 1987;117:1-6.

3. Lannerstein L, Harms-Ringdahl K. Neck and shoulder muscle activity during work with different cash register systems. Ergonomics 1990;33:49-65.

4. Hünting W, Läubli T, Grandjean E. Postural and visual loads at VDT workplaces I. Ergonomics 1981;24:91731.

5. Zeier $\mathrm{H}$, Mion H, Läubli T, Senn E. Augen- und Rückenbeschwerden bei Bildschirmarbeit in Abhängigkeit von ergonomischen und biopsychosozialen Faktoren. Z Exp Angew Psychol 1987;34:155-79.

6. Zeier H, Mion H, Läubli T, Thomas C, Fasser W, Senn E. Subjective reports about musculoskeletal discomfort in VDU work as a complex phenomenon. In: Knave B, Widebäck P-G, ed. Work with display units 86 . North Holland: Elsevier Science Publishers BV, 1987:263-78.

7. Krueger H, Conradi P, Zülch J. Work with magnifying glasses. Ergonomics 1989;32:785-94.

8. Mion H, Läubli T, Senn E, Zeier H: Beschwerden im Bewegungsapparat. Der informierte Arzt/Gazette Médicale 1986;5:62-8.

9. Stoffert G. Analyse und Einstufung von Körperhaltungen bei der Arbeit nach der OWAS-Methode. Z Arbeitswiss 1985;39:31-8.

10. Rohmert W, Löwenthal I, Rükert A. Körperhaltungsstudie bei Lade- und Palettierungstätigkeiten auf einem Grossflughafen. Arbeitsmed Sozialmed Präventivmed 1988;23:91-6.

11. Kant I, Notermans JHV, Borm PJA. Observations of working postures in garages using the Ovako Working Posture Analyzing System (OWAS) and consequent workload reduction recommendations. Ergonomics 1990;33:209-20.

12. Fleischer A G, Lange W. Analysis of hand movements during the performance of positioning tasks. Ergonomics 1983;26:555-64.

13. Guggenbühl U, Krueger H. Bewegungsanalyse an verschiedenen industriellen Arbeitsplätzen. Soz Präventivmed 1987;32:266-68.

14. Nie N, Hull C, Jenkins J, Steinbrenner K, Bent D. SPSS statistical package for the social sciences. New York, NY: McGraw Hill Book Company, 1975.

15. Computing Resource Center. STATA. Reference manual release 2. Los Angeles, CA: Computing Resource Center, 1989.

Received for publication: 1 October 1991 